\title{
Use of Baltic Sea modelling to investigate the water cycle and the heat balance in GCM and regional climate models
}

\author{
A. Omstedt ${ }^{1,2, *}$, B. G ustafsson ${ }^{2}$, J . Rodhe ${ }^{2}$, G. Walin' ${ }^{2}$ \\ ${ }^{1}$ Swedish Meteorological and Hydrological Institute, 60176 Norrköping, Sweden \\ ${ }^{2}$ Department of Earth Sciences, University of G öteborg, Earth Sciences Centre, Box 460, 40530 G öteborg, Sweden
}

\begin{abstract}
Results from the first simulations with the Rossby Centre regional climate atmosphere (RCA) model were used to force 2 versions of process-oriented models of the Baltic Sea-one timedependent, the other considering the mean state. The purpose was primarily to obtain a first scenario of the future state of the Baltic Sea. In addition, we looked at this exercise as a method to evaluate the consistency of the water cycle and the heat balance produced by atmospheric climate models. The RCA model is a high-resolution atmospheric regional model which is forced with lateral conditions from a global model. A large-scale Baltic drainage basin hydrological model, forced by the RCA model, was used to simulate river runoff. Using RCA model data from the control run we found that that the temperature and ice conditions in the Baltic Sea were reasonably realistic while the salinity field was poorly reproduced. We conclude that the modelling of the water cycle needs considerable improvement. We also conclude that the time for the Baltic Sea to respond to the water cycle is much longer than the integration period so far used with the RCA model. Forcing the ocean models with RCA model data from a future scenario with an enhanced greenhouse effect gives an increased sea-surface temperature and a much reduced extent of ice in the Baltic Sea due to climate warming. Also the salinity is reduced, which implies possible serious effects on the future marine life in the Baltic Sea. The results demonstrate that accurate atmospheric modelling of not only the heat balance but also the water cycle is crucial for Baltic Sea climate simulations.
\end{abstract}

KEY WORDS: Baltic Sea $\cdot$ Climate change $\cdot$ Temperature $\cdot$ Sea ice

\section{INTRODUCTION}

The Earth's climate system is at present analysed with global numerical models for the ocean, atmosphere, and cryosphere and land surface, often referred to as general circulation models (GCM s). The interpretation of this type of models indicates surface warming associated with increased levels of greenhouse gases. However the amplitude differs depending on region as well as on the model used (Schuurmans et al. 1995, IPPC 1996). Numerical simulations of the climate in the Nordic Countries (Räisänen 1994, 2000, J ohannesson et al. 1995) indicate an increase both in air temperature

*E-mail: anders.omstedt@smhi.se and in precipitation during the next $100 \mathrm{yr}$. However, the coarse resolution in the climate GCM s make predictions of the regional climate questionable. Therefore various methods, statistical as well as dynamical, are needed in order to increase the quality of regional climate simulations.

Our ability to understand and predict the climate system and climate change depends critically on our capability to observe and model the processes governing the water cycle and the heat balance. The water cycle and the heat balance of the northern Europe are affected by a number of small-scale features, as, for example, the complex coastlines, islands and numerous lakes, as well as the complexities of the Baltic Sea estuary. As a consequence, there is insufficient knowledge today about these cycles, with regard to observations as well as models (BALTEX 1995). Anyhow, 


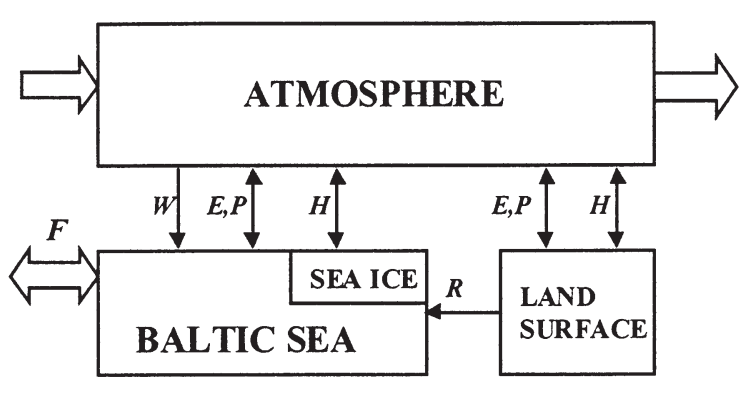

Fig. 1. Principal coupling mechanisms between the atmosphere, land surface and Baltic Sea. E and P denote evaporation and precipitation respectively, $\mathrm{F}$ in- and outflows through the Danish Straits, $\mathrm{H}$ heat fluxes including radiation, $\mathrm{R}$ river runoff and $\mathrm{W}$ the wind energy

studies of water and heat cycles have a long tradition in the countries surrounding the Baltic Sea, which thereby provides an excellent region for climate studies. The Baltic drainage basin, with a total area of about $1.7 \times 10^{6} \mathrm{~km}^{2}$, can be used as a huge rain gauge or test site for climate modelling. The closing of the atmospheric water and heat balances can be done by considering the net fluxes from the drainage basins through the straits of the Baltic Sea entrance area (Fig. 1). Baltic Sea modelling can therefore serve as an important component for the validation of the atmospheric and land-surface models by closing the water and heat balance over the whole drainage basin. This idea will be further explored in the present paper, in which we apply Baltic Sea modelling in order to review the water cycle and the heat balance in climate atmosphere models.

The aim of this paper is to analyse the results from the Rossby Centre regional climate atmosphere (RCA) model with respect to the description of the water cycle and the heat balance. The atmospheric model is a regional climate version of HIRLAM (Källén 1996), forced on the lateral boundaries by results from the global model from the Hadley Centre (HadCM 2). The river runoff is calculated with a large-scale hydrological model, the HBV-Baltic model (Graham 1999), and forced by the RCA model. The Baltic Sea modelling is based on the time-dependent PROBE-Baltic model (Omstedt \& Nyberg 1996) and the mean-state model of Gustafsson (1997), both forced by the RCA and the HBV-Baltic models.

In Section 2, the development of Baltic Sea modelling is reviewed. The meteorological and hydrological forcing fields that will be evaluated are presented in Section 3, together with a short description about the implementation of the Baltic Sea models. The results are presented in Section 4. A discussion related to Baltic Sea climate modelling is given in Section 5 . Finally, some conclusions are drawn in Section 6.

\section{BACKGROUND}

The Baltic Sea water exchange has been extensively studied during the twentieth century. In the pioneering work of Knudsen $(1899,1900)$, the long-term average exchange through the straits was described as a 2-layer flow with the outflow in the upper layer and inflow in the lower. Knudsen found that the transport at the entrance should be the double of the river runoff in the upper layer and equal to the river runoff in the lower layer in order to fulfil the requirement of salt conservation. J acobsen (1925) related the water exchange of the Baltic Sea to surface-current observations from lightships. He suggested that the exchange is proportional to the surface currents at the Drogden Sill. Wyrtki (1954) and Soskin (1963) further refined the method. However, this method has severe deficiencies for determining long-term exchange, partly because the observations are likely to contain substantial errors due to the simple measuring techniques and partly because of poorly known lateral variations. Also the baroclinic component of the exchange may be of considerable importance (see discussion in J acobsen 1980).

In Knudsen (1899), the first attempt to model the water exchange through the straits was presented. Knudsen related measured currents at the sills to the air pressure over the Baltic Sea and to the winds over Skagerrak, Kattegat and the southern Baltic Sea. He realised that the main driving of the flow is the sealevel variations forced by wind and air pressure variations. He did not, however, take into account the storage of water in the Baltic Sea, which produced considerable errors. Witting (1918) calculated the monthly water exchange between 1898 and 1912 from volumeconservation principles using sea-level observations, evaporation calculations, precipitation observations and river runoff data. Bergsten (1933) (according to J acobson 1980) introduced the assumption that a balance between an along-channel pressure gradient (sea-level gradient) and bottom friction can describe the flow through the straits. This essentially implies that the flow should be proportional to the square root of the sea-level difference between southern Baltic Sea and the Kattegat. This, and refined versions of it, has lately become the most frequently used description of the flow through the straits (for reviews see J acobsen 1980 and Gustafsson 1997).

Stigebrandt (1983) made the first prognostic simulation of the water and salt exchange in a manner that was suitable for climate impact analysis. His timedependent model reproduced the stratification of the Kattegat and the Belt Sea quite accurately as a function of observed sea level, river runoff and wind. The model featured several new insights into the dyna- 
mics of the Baltic Sea entrance area. The most fundamental was the idea that both the outflow from the surface layer of Kattegat and from the lower layer of the Belt Sea into the Baltic are in geostrophic balance. This balance constitutes a dynamic constraint at the Kattegat-Skagerrak front, which is a key factor for the whole Baltic Sea water exchange (Gustafsson 1997, J acobsen 1997). Further, Stigebrandt (1983) presented functional dependencies between the Baltic Sea surface salinity and climate variations in freshwater supply, local wind, sea-level variability and Skagerrak salinity. Stigebrandt's model concept was later refined and extended by Omstedt (1987, 1990), Omstedt \& Nyberg (1996), Omstedt \& Axell (1998) and Gustafsson $(2000 a, b)$. Stigebrandt's results concerning the sensitivity of Baltic Sea salinity have been confirmed by Gustafsson (1997, 2000b). The modelling of the heat (including sea ice) and water cycles of the Baltic Sea have been reviewed by Omstedt \& Rutgersson (2000).

The efforts to numerically model the Baltic Sea have expanded rapidly during the last years, and include several investigations using 3-dimensional models, for example, Winkel-Steinberg et al. (1991), Huber et al. (1994), Lehmann (1995), Meier (1996 1999), Sayin \& Krauss (1996), Schrum \& Backhaus (1999) and Lehmann \& Hinrichsen (2000). A problem with the grid models of the area is the enormous computational effort needed to resolve the short lateral scales of the baroclinic currents and strait flows. We can, however, hope for more progress in this field as computer capacity increases and new, more physically correct parameterisations of unresolved processes are developed.

\section{INVESTIGATION OF THE CLIMATE MODELS}

3.1. Atmosphere simulations. Forcing fields for the control run and the scenario run (Table 1) were obtained from atmospheric simulations with an RCA model, i.e. the Rossby Centre regional climate atmosphere model (Rummukainen et al. 1998, Räisänen et al. 1999). The RCA model was thereby used to downscale fields produced by the global ocean-atmosphere model
HadCM 2 (J ohns et al. 1997, Räisänen \& Döscher 1998). The grid size in the RCA model is $44 \mathrm{~km}$ while the HadCM 2 model is much coarser with a grid size around $250 \mathrm{~km}$ at $60^{\circ} \mathrm{N}$.

The 2 simulations with the HadCM 2 model were run for $140 \mathrm{yr}$ (1860 to 2100). The first simulation (control run) was performed with constant, pre-industrial greenhouse gas composition. In the second simulation (scenario run) the greenhouse gas composition was prescribed according to measurements up to 1990 and thereafter increasing $1 \% \mathrm{yr}^{-1}$. For the RCA model downscaling simulations $10 \mathrm{yr}$ periods in the middle of the HadCM 2 model runs (2039 to 2049) were chosen.

3.2. River-runoff simulations. The river runoff was simulated with a large-scale hydrological model (the HBV-Baltic model, Graham 1999). The model was forced by daily mean temperature and precipitation results from the RCA model simulations. The river runoff for both the control and the scenario runs was simulated. The HBV model (Bergström 1995, Lindström et al. 1997) was originally developed more than $25 \mathrm{yr}$ ago (Bergström \& Forsman 1973) and has been applied in a large number of studies. The modelling approach is to divide the land into natural sub-basins based upon catchment areas. Within each sub-basin, discretization into elevation zones and land use is carried out. The HBV model is organised as a series of boxes connected by fluxes that describe the main physical processes such as snow, rain, evapotranspiration, and runoff. The model has been proven to be robust over a wide range of scales up to the size of the Baltic catchment area (Bergström \& Graham 1998). The model has recently been applied to evaluate runoff generation processes in other atmospheric GCM climate models (Graham \& J acob 2000).

3.3. Baltic Sea simulations. The Baltic Sea model PROBE-Baltic (Omstedt \& Nyberg 1996) was applied using the different forcing data without any feedback on the atmosphere or land surface. The model divides the Baltic Sea into 13 sub-basins based upon bottom topography as illustrated in Fig. 2. The properties of each sub-basin are calculated in terms of horizontal mean values of temperature, salinity, and ice-cover making use of the $k-\varepsilon$ turbulence model. Further, each

Table 1. Baltic Sea climate simulations forcing the PROBE-Baltic model with different data sets. RCA model: regional climate atmosphere model. HBV-Baltic: regional river-runoff model

\begin{tabular}{|lccccc|}
\hline \multirow{2}{*}{ Run number } & Meteorological forcing & River runoff & Sea levels & Initial conditions & Comments \\
\hline (1) Standard & Observed & Observed & Observed, 1980-95 & 1 Nov 1980 & $15 \mathrm{yr}$ \\
(2) Control & RCA model & HBV-Baltic model & Observed, 1985-95 & 1 Nov 1980 & $10 \mathrm{yr}$ \\
(3) Scenario & RCA model & HBV-Baltic model & Observed, 1985-95 & 1 Nov 1980 & $10 \mathrm{yr}$ \\
& & & & & $100 \mathrm{yr}$ \\
& & & & & \\
\end{tabular}




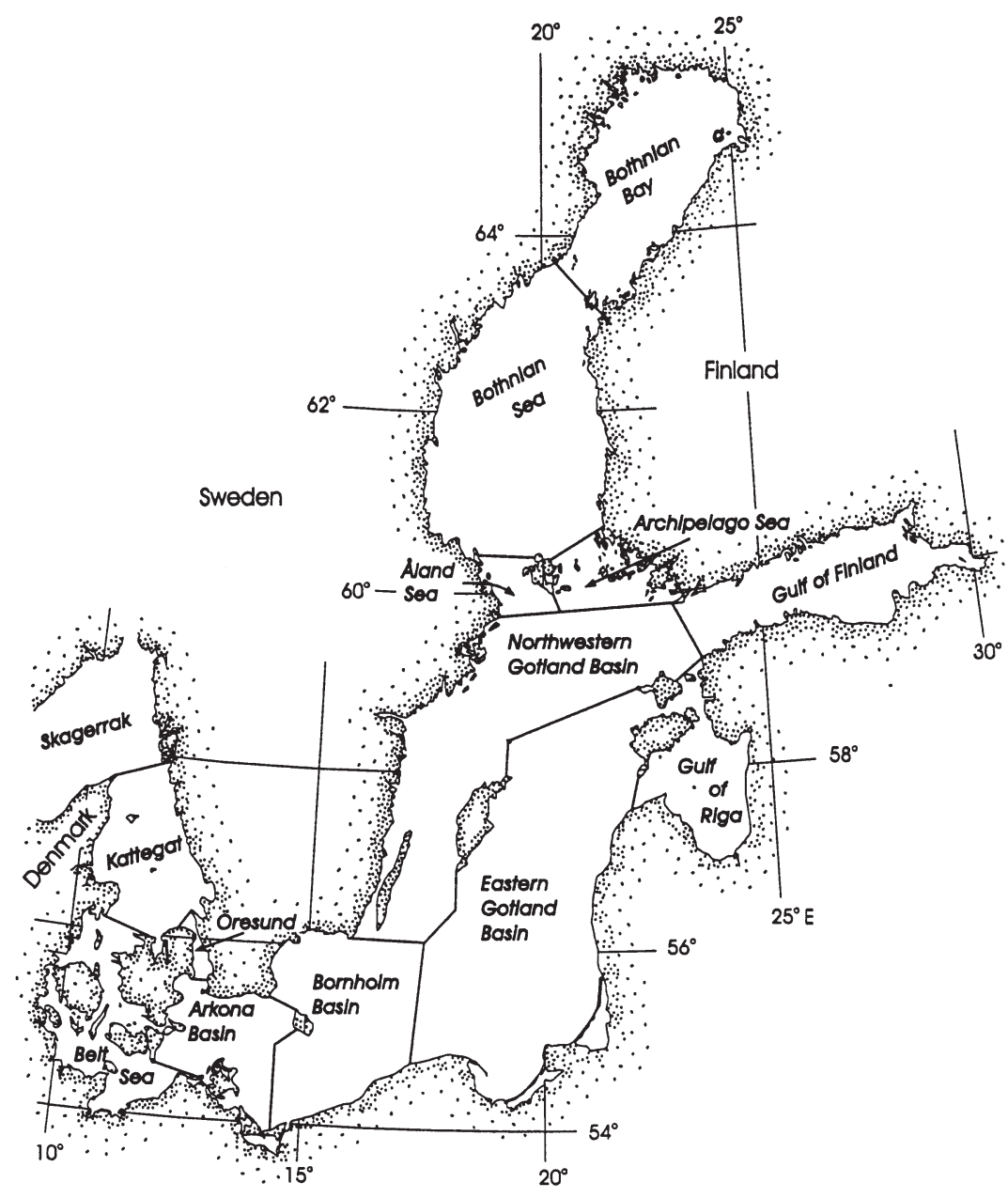

Fig. 2. The Baltic Sea and Skagerrak system with sub-basins used in the PROBE-Baltic model olution, were used to force the ocean model. The river runoff was based on calculations from the HBV-Baltic model, where the RCA model forcing fields were used. In all ocean calculations the same initial conditions were applied, corresponding to the observed conditions in November 1980. Also the same lateral boundary conditions were applied in all runs, which means that the in- and outflows through the Baltic entrance area were forced by sea-level data from the Kattegat and that the deep-water temperature and salinity in the Kattegat were kept constant.

To investigate the steady-state salinity response to the atmospheric and river-runoff forcing, the ocean model developed by Gustafsson (1997) was applied. In this analytical model the upper layer of the Kattegat and Belt Sea are treated as a single water mass, while the lower layer is treated as dynamically passive source of water and salt. The coupling to surrounding sub-basins includes a geostrophic outflow to the Skagerrak, entrainment flow from the lower layer, fluctuating flow across the sills and freshwater input from the Baltic Sea. One major result from the model is the surface salinity in the outflow water from the Baltic Sea. In the model the river runoff was based on calculations from the HBV-Baltic model; the precipitation and evaporation were based on simulations from the RCA and PROBE-Baltic models respectively.

\section{RESULTS}

\subsection{Introduction \\ 4.1. Introduction}

precipitation rates were calculated from 10 different regions of the Baltic Sea (Omstedt et al. 1997). Further, observed monthly mean river runoff to the Baltic Sea (Bergström \& Carlsson 1994) and daily mean sea level in the Kattegat were used. The PROBE-Baltic model has been proven to realistically simulate sea-surface temperatures, sea ice, and the vertical structure of temperature and salinity (e.g. Omstedt \& Axell 1998). The quality of the model will be further discussed in Section 4.

For the climate control and scenario simulations (Table 1) the $10 \mathrm{yr}$ RCA model runs, with $6 \mathrm{~h}$ time res-
In this section, we present the results from some different simulations with the ocean models (Table 1). First the sea-surface temperatures from some subbasins are studied. The corresponding results for sea ice are then analysed. The water balance for the whole Baltic Sea is then studied based on the RCA model control and scenario runs and compared with observations and calculations from the global climate model ECHAM 4 (Stendal \& Roeckner 1998). The corresponding salinity response is also examined by calculating the steady-state Baltic Sea surface salinity according to 

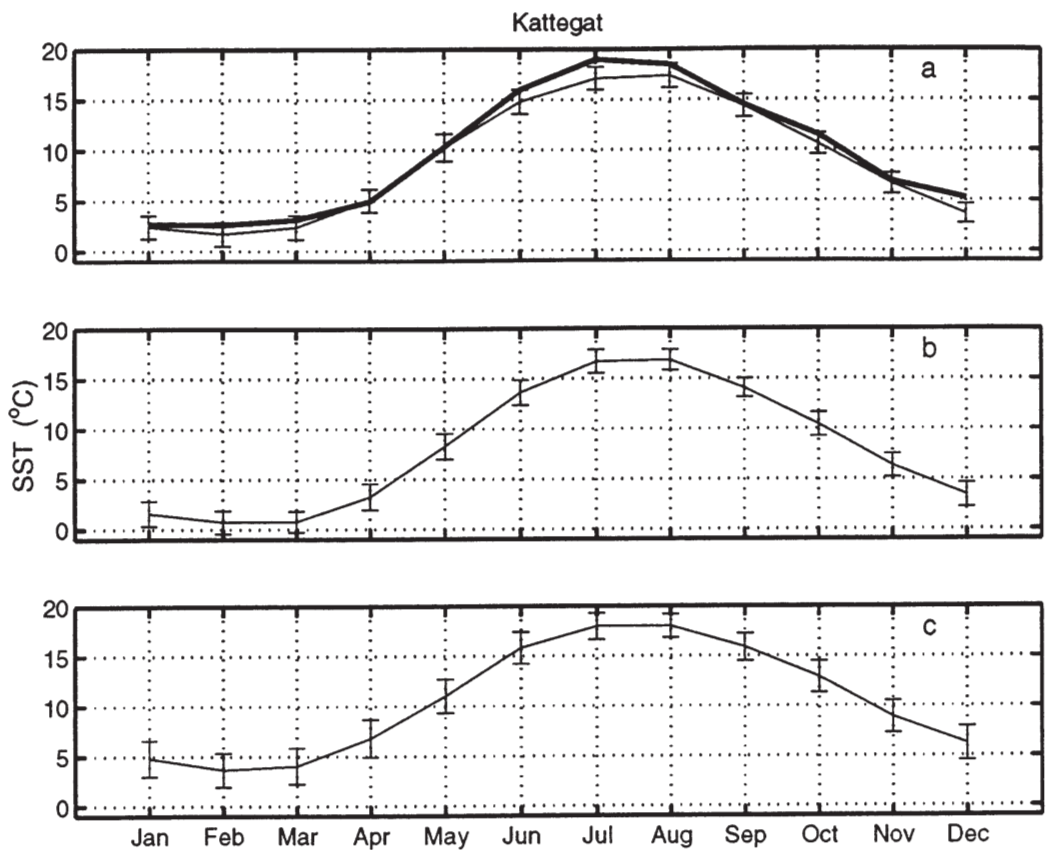

Fig. 3. Calculations of monthly-mean sea-surface temperatures in the Kattegat according to: (a) the standard run (thin line) together with observations (thick line), (b) the control run and (c) the scenario run. Error bars: SD in the calculations (from $10 \mathrm{yr}$ ). For the different runs see Table 1. The observed data are based on observations from Stn Anholt East in the Kattegat and performed by the Swedish Coast Guard during the period 1984 to 1998 perature (Rummukainen et al. 1998). In this way the surface climate properties from the RCA model control run became more realistic. In the section we use the meteorological forcing fields from the RCA model calculations and calculate the sea-surface temperatures with the PROBE-Baltic ocean model. The results illustrate what one could expect if an ocean model were linked to the RCA model.

The monthly-mean sea-surface temperatures simulated by the PROBEBaltic model from selected sub-basins are shown in Figs. 3 to 5. The model calculations for the standard run are also verified with climate data (Figs. 3a, $4 a \& 5 a)$. The data are based upon observations at some standard hydrographic stations and averaged over a 15 to $20 \mathrm{yr}$ period during present climate conditions. The simulated seasurface temperatures are close to the observed data, but slightly too cold, particularly during winter and spring seasons. The mean error and root mean
Gustafsson (1997). Finally, the vertical salinity structures are examined based on the RCA model scenario run and a 100 yr Baltic Sea simulation.

\subsection{Sea-surface temperatures}

In the RCA model calculations, no ocean or lake models were applied. Instead the sea-surface temperatures in the Baltic Sea and Skagerrak region were taken from the HadCM 2 model calculations, which were in general too warm during winter and too cold during summer. Due to its horizontal coarseness the HadCM 2 model did not include ice in the Baltic Sea or in the Nordic lakes. In some earlier test runs, the use of the sea-surface temperatures from the HadCM 2 model model caused severe problems when simulating a realistic Nordic surface climate. To overcome these problems tuned ice-proxy models for the Baltic Sea and for the lakes were introduced based on the closest HadCM 2 model monthly mean soil tem-
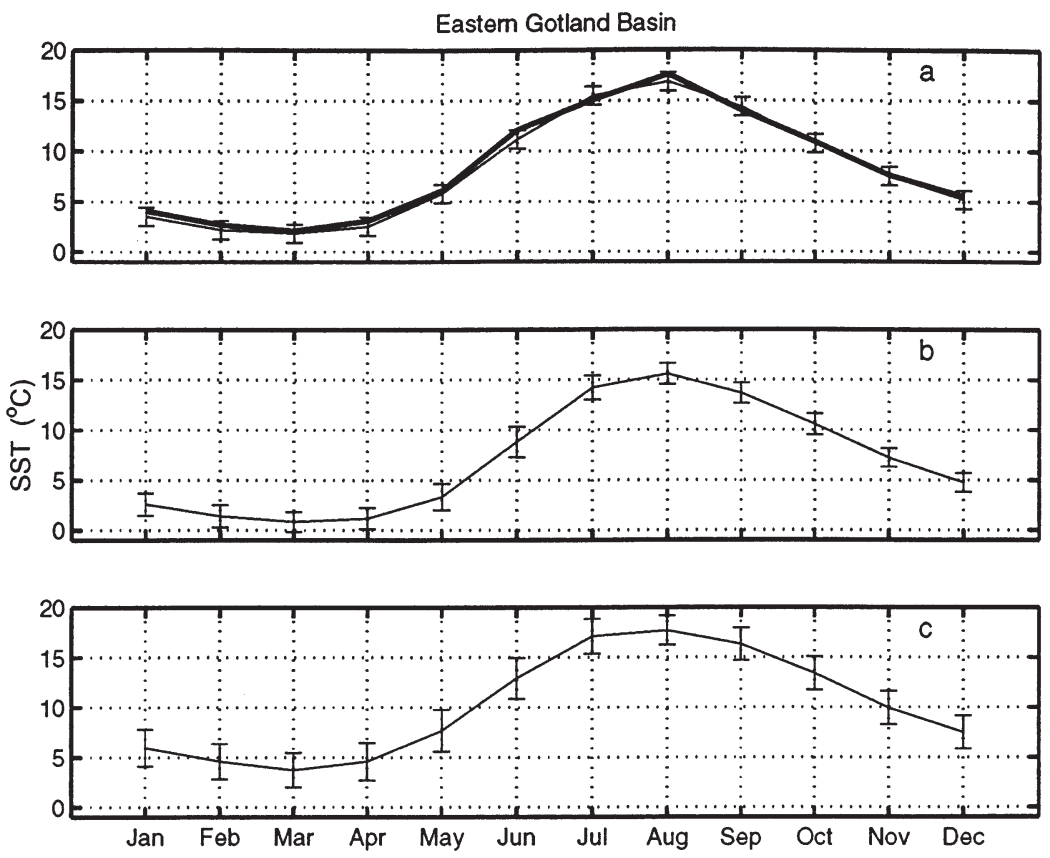

Fig. 4. Calculations of monthly-mean sea-surface temperatures in the Eastern Gotland Basin according to: (a) the standard run (thin line) together with observations (thick line), (b) the control run and (c) the scenario run. Error bars: SD in the calculations (from $10 \mathrm{yr}$ ). For the different runs see Table 1. The observed data are based on observations from Stn BY 15 in the Eastern Gotland Basin and performed by the Swedish Coast Guard during the period 1974 to 1998 

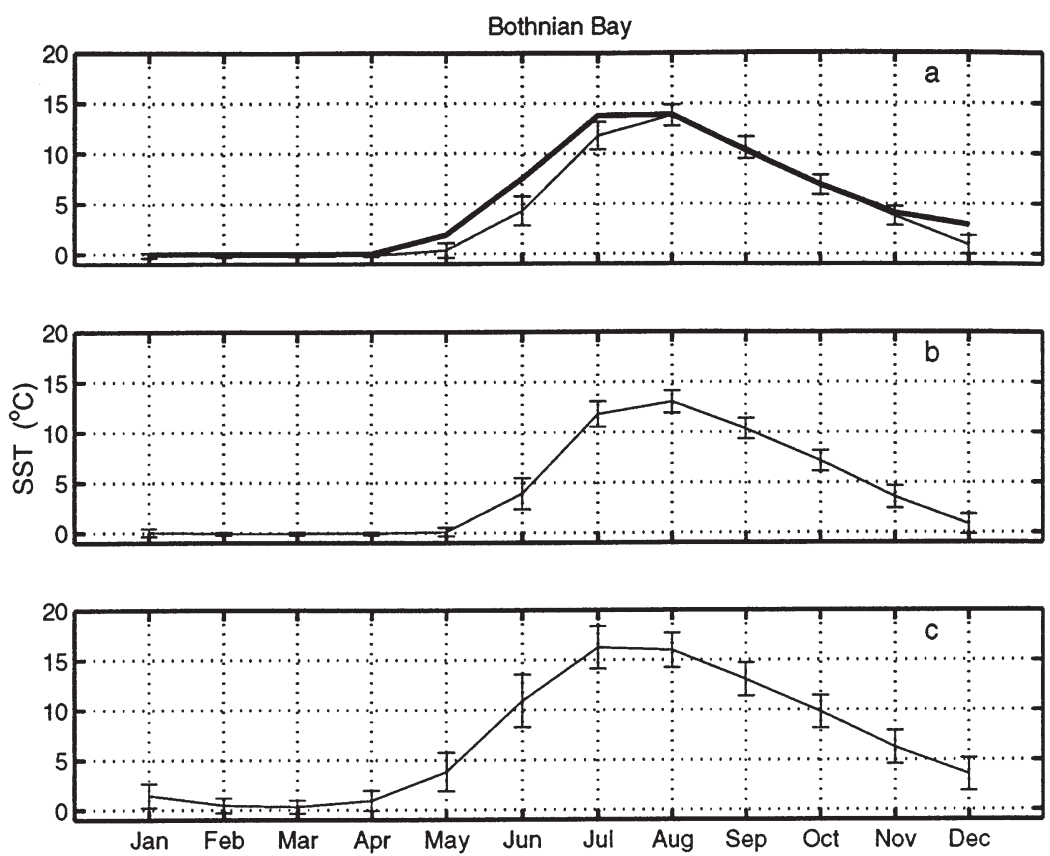

Fig. 5. Calculations of monthly-mean sea-surface temperatures in the Bothnian Bay according to: (a) the standard run (thin line) together with observations (thick line), (b) the control run and (c) the scenario run. Error bars: SD in the calculations (from $10 \mathrm{yr}$ ). For the different runs see Table 1 . The observed data are based on observations from Stn F9 in the Bothnian Bay and performed by the Swedish Coast Guard during the period 1973 to 1998

square error between the standard run and the observations are typically -1 and $1^{\circ} \mathrm{C}$ respectively.

The sea-surface temperatures in the control run show a realistic seasonal cycle and realistic winter temperatures at freezing. However, the control run is slightly colder than the standard run particularly during winter and spring seasons (Figs. 3b, $4 b \& 5 b$ ). The corresponding calculations from the scenario run show similar seasonal cycles but with higher sea-surface temperatures, particularly during the winter season (Figs. 3c, 4c \& 5c). During the summer seasons the scenario run also indicates an increased temperature. If an ocean model were coupled with the RCA model one could thus expect a quite realistic sea-surface-temperature evolution during the control run and a strong change in the scenario run. The implications on the extent of sea ice will be discussed in the next subsection.

\subsection{Sea ice}

The modelled extent of sea ice using the PROBEBaltic ocean model and observed meteorological fields (standard run) is illustrated in Fig. 6. In the figure some limits for the present climate conditions (based on the period 1720 to 1997) are also shown. The classification of the ice winters follows that by Seinä \& Palosuo (1993) and the figure illustrates that the period 1980 to 1995 includes both mild, normal and extremely severe ice winters. The model simulation shows high skill, with a mean error of $13 \times 10^{3}$ $\mathrm{km}^{2}$ (model overestimation of about $7 \%$ ) and a root square mean error of $32 \times 10^{3} \mathrm{~km}^{2}$.

The corresponding simulations using control and scenario forcing fields are given in Fig. 7. The control run (Fig. 7a) shows that the ice extent is reasonably realistically simulated. However, the control run show a bias towards a slightly larger ice extent compared to the climate mean. For the RCA model scenario run (Fig. 7b), the annual maximum extent of ice is much reduced, indicating a large change in Baltic Sea winter conditions. Several studies on the extent of ice and climate change are available, illustrating a strong impact on the extent of ice during climate warming (Seinä 1993, Haapala \& Leppäranta 1996, 1997, Tinz 1996, 1998, Omstedt \& Nyberg 1996). As ice formation is due to a sensitive balance between net heat loss and mixing, any estimation of strongly reduced sea-ice cover should be studied with great care. However, it is interesting to notice that the scenario run indicates a maximum extent of ice close to the observed long-term minimum and that there is almost no ice during 3 out of 10 winters. From earlier calculations using the PROBE-Baltic model it was learned that with an air-temperature increase of $+3^{\circ} \mathrm{C}$ (reference period: 1981 to 1995), the maximum annual extent of ice could be expected to become zero during 1 out of 15 winters. With such a large climate warming as simulated by the RCA model, it is thus most likely that the Baltic Sea will become completely ice-free during some winters.

\subsection{Water cycle and heat balance}

Some different estimates of the Baltic Sea water cycle and heat balance are given in Table 2 . In the study by Omstedt \& Rutgersson (2000), evaporation rates were calculated using the PROBE-Baltic ocean model forced by observed data for the period 1980 to 1995. This simulation illustrated that the long-term water balance was consistent with the salinity of the 


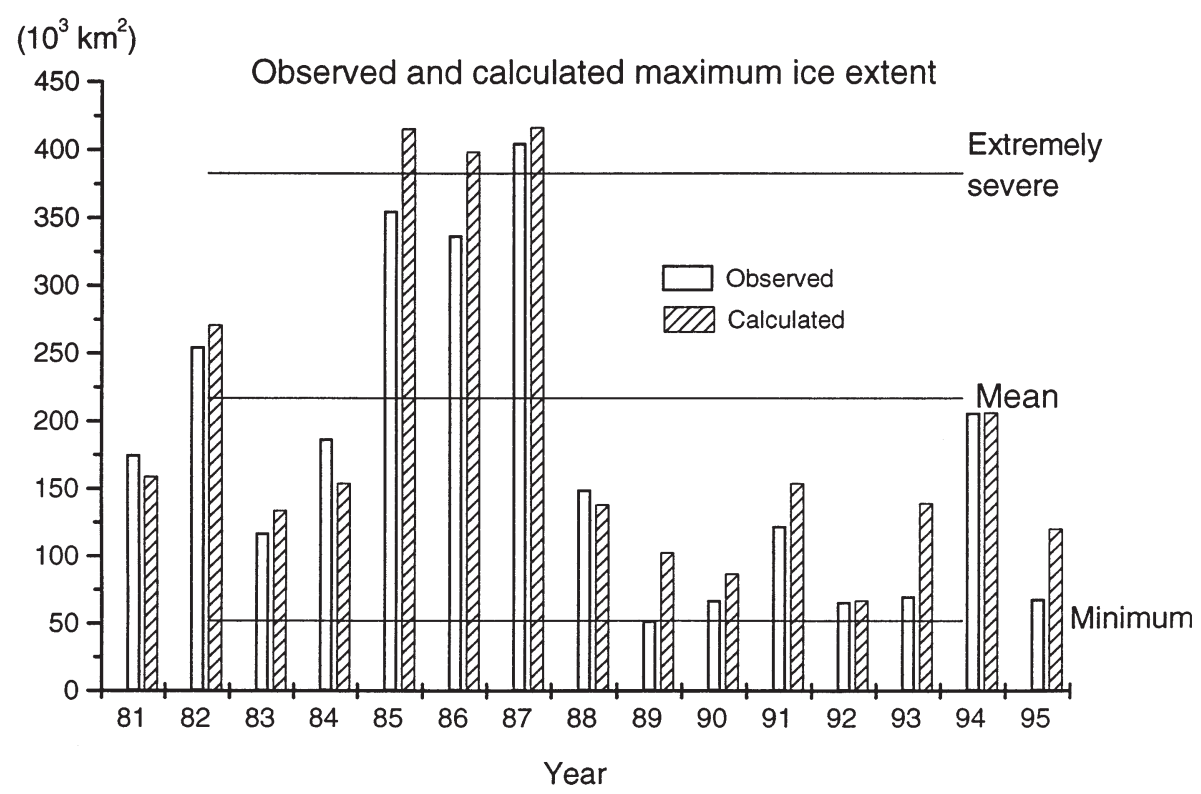

Fig. 6. Observed annual maximum extent of ice and calculations using the PROBE-Baltic model and observed forcing fields (standard run)

Baltic Sea (Omstedt \& Axell 1998) and is therefore regarded as a good estimation of the present (1980 to 1995) climate conditions. The ECHAM 4 model simulations for the Baltic Sea were reported by J acob et al. (1997) and are given for 2 different runs in the table. The long-term heat balance from the ECHAM 4 model simulations reported by J acob et al. (1997) was also discussed in the analysis by Omstedt \& Rutgersson (2000). Earlier estimations of the water balance of the Baltic Sea are given in HELCOM (1986). Finally in Table 2, the water-balance components from the RCA model simulations are shown. In these calculations the river runoff was calculated using the HBV-Baltic model and using RCA model forcing fields. The evaporation rates were calculated using the PROBE-Baltic model and forced by the RCA model runs. The steadystate salinities of the Baltic Sea were calculated using the model in Gustafsson (1997) and represent the surface salinities of the outflowing water from the Baltic Sea.

In Table 2, one can notice that the RCA model control and scenario runs, as interpreted from the PROBEBaltic model, give high net precipitation rates (precipitation minus evaporation) over the Baltic Sea. The

Table 2. A comparison between some estimates of the long-term mean water balance of the Baltic Sea (not including the Kattegat and the Belt Sea), where $P$ is the precipitation rate, $E$ the evaporation rate, $Q_{r}$ the river runoff, $A_{S}(P-E)$ the net precipitation, $Q_{\text {sum }}=Q_{r}+A_{S}(P-E)$, and $S$ the surface salinity of the Baltic Sea

\begin{tabular}{|c|c|c|c|c|c|c|}
\hline $\begin{array}{l}P \\
(m)\end{array}$ & $\begin{array}{l}E \\
(m)\end{array}$ & $\begin{array}{c}A_{S}(P-E) \\
\left(10^{3} \mathrm{~m}^{3} \mathrm{~s}^{-1}\right)\end{array}$ & $\begin{array}{c}\mathrm{Q}_{\mathrm{r}} \\
\left(10^{4} \mathrm{~m}^{3} \mathrm{~s}^{-1}\right)\end{array}$ & $\frac{Q_{\text {sum }}}{\left(10^{4} \mathrm{~m}^{3} \mathrm{~s}^{-1}\right)}$ & $\begin{array}{c}\mathrm{S}^{\mathrm{a}} \\
(\mathrm{psu})\end{array}$ & Source \\
\hline 0.60 & $0.44^{\mathrm{b}}$ & 1.87 & $1.51^{\mathrm{c}}$ & 1.70 & 7.06 & Omstedt \& Rutgersson (2000) \\
\hline 0.83 & 0.50 & 3.77 & 1.53 & 1.91 & 6.28 & J acob et al.(1997), Run 1 \\
\hline 0.85 & 0.56 & 3.46 & 1.57 & 1.92 & 6.23 & Jacob et al.(1997), Run 2 \\
\hline 0.58 & 0.44 & 1.26 & 1.38 & 1.51 & 7.92 & HELCOM $(1986)^{d}$ \\
\hline 0.65 & $0.36^{\mathrm{e}}$ & 3.41 & $1.88^{f}$ & 2.22 & 5.34 & Control run, RCA model \\
\hline 0.84 & $0.47^{e}$ & 4.42 & $2.10^{f}$ & 2.54 & 4.56 & Scenario run, RCA model \\
\hline \multicolumn{7}{|c|}{ 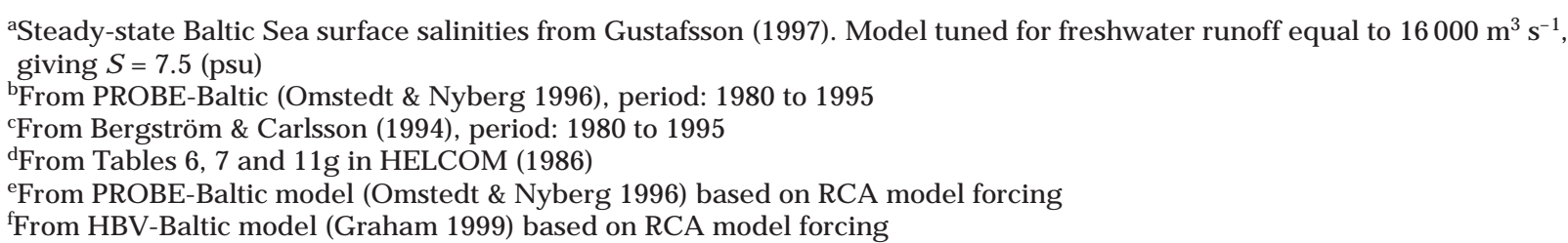 } \\
\hline
\end{tabular}



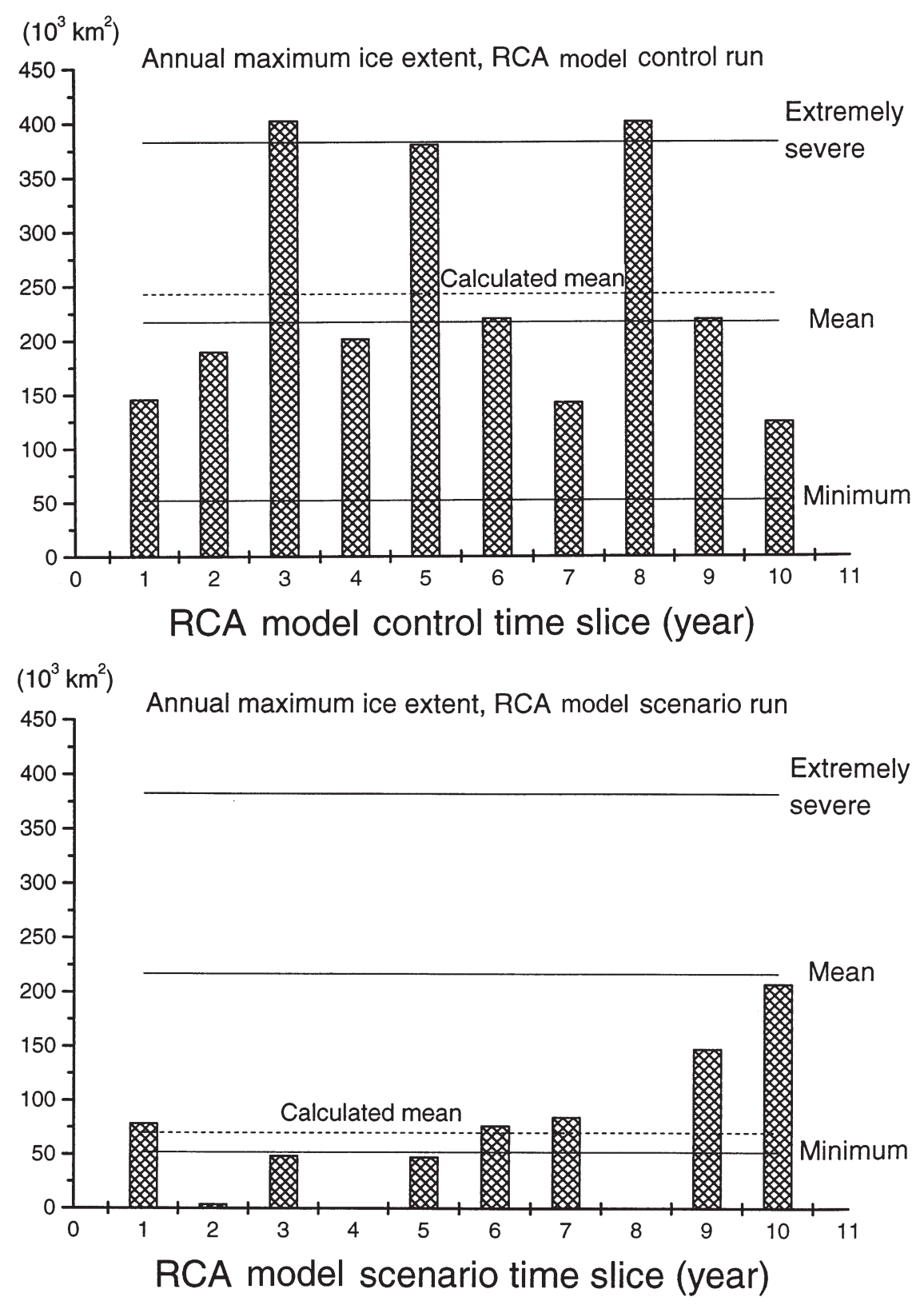

Fig. 7. Calculated annual maximum extent of ice using (a) control and (b) scenario forcing fields

corresponding river-runoff calculations also indicate high rates. In the RCA model control run the total freshwater input to the Baltic Sea was calculated as $2.22 \times 10^{4} \mathrm{~m}^{3} \mathrm{~s}^{-1}$, which is about $5000 \mathrm{~m}^{3} \mathrm{~s}^{-1}$ more than one would expect for the present climate conditions. The total freshwater input in the scenario run was 2.54 $\times 10^{4} \mathrm{~m}^{3} \mathrm{~s}^{-1}$ or about $8000 \mathrm{~m}^{3} \mathrm{~s}^{-1}$ more than that with present climate conditions. The freshwater input in the control run, and probably also in the scenario run, is thus clearly too high. This illustrates that the water cycle of the atmosphere and land surface models needs to be improved.

\subsection{Vertical structure of salinity}

The stratification of the Baltic Sea is strongly dependent on salinity. Winsor et al. (2000) have demonstrated that the salinity at the Gotland Deep (Stn BY 15) represents the Baltic Sea salt content very well. We will therefore evaluate the response in salinity due to the different forcing fields by showing the results from the Eastern Gotland Basin (Fig. 2). The observed salinity data together with simulated values based upon the PROBE-Baltic model and observed forcing (standard run) are given in Fig. 8. Based upon the difference 
a) The Gotland Deep observed salinity

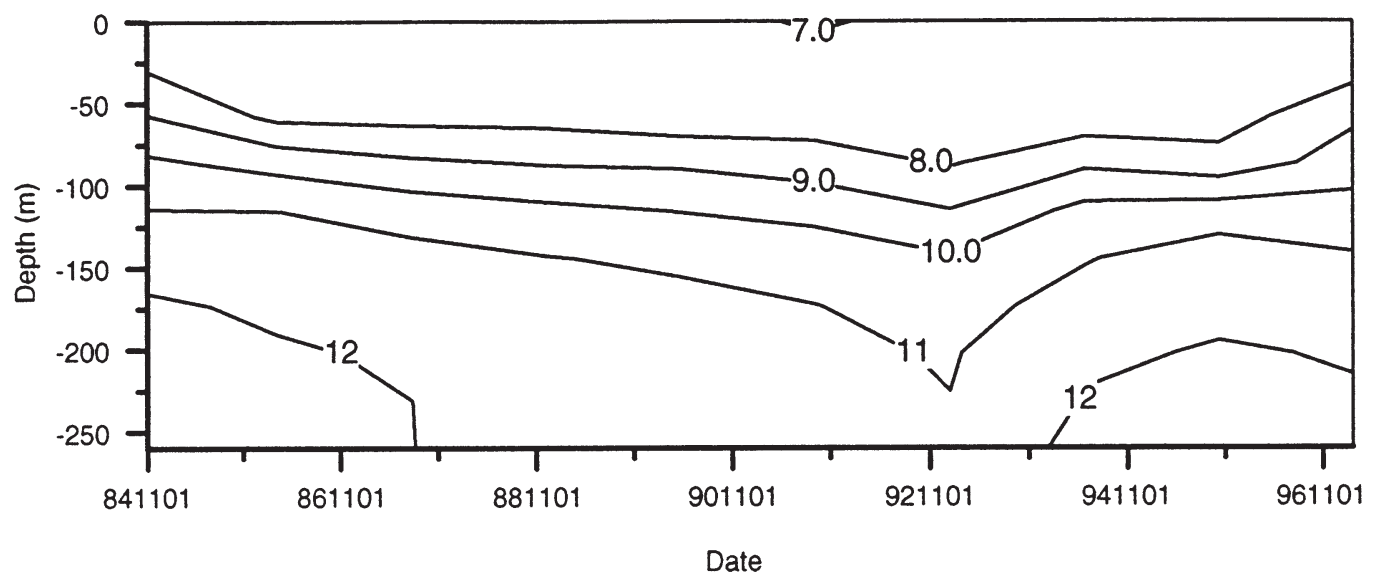

b) The E. Gotland Basin salinity, standard run

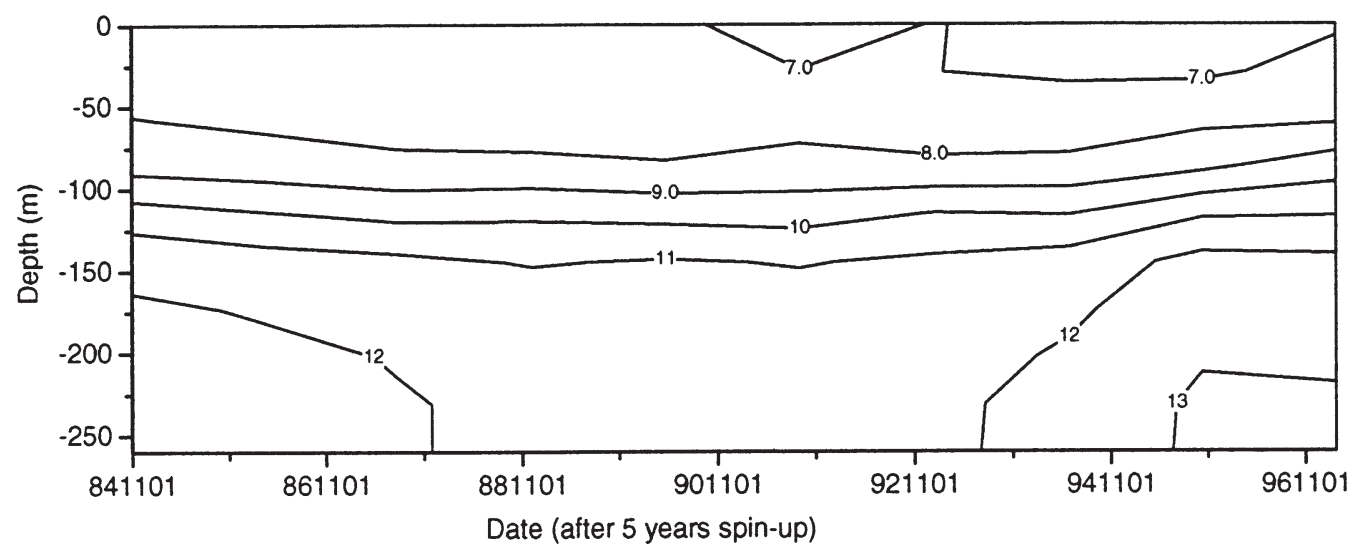

Fig. 8. (a) Observed vertical structure of salinity in the Eastern Gotland Basin and (b) calculations based on observed forcing fields (standard run). Dates: yymmdd

between the modelled and the observed median profiles of salinity the mean error and root mean square error were +0.013 and 0.263 psu, respectively (Omstedt \& Axell 1998). During the illustrated period, only 1 major inflow event occurred. This event can be observed (Fig. 8a,b) as increased bottom salinity, starting at end of 1992. In the simulation the bottom salinities were, however, slightly overestimated during this inflow event.

The Baltic Sea transient salinity responses for the control and scenario runs are illustrated in Fig. 9. In the control run (Fig. 9a) the calculations show that the salinity is reduced compared to the standard run. The simulated salinities in the scenario run (Fig. 9b) are reduced even more, which can be noticed particularly in the surface layers. However, also the deep layers become fresher. It should be noticed that the modelled salinities drift towards lower values. This is due to the long stratification spin-up time, which is typically $100 \mathrm{yr}$ for the Baltic Proper (Omstedt \& Axell 1998). The calculations in Fig. 9 are thus much influenced by the initial conditions and they are not in balance with the freshwater supply. A comparison with the steady-state salinities in Table 2 indicates that much longer time periods are needed before the Baltic Sea adjusts to the forcing. Hence, the use of short time periods for simulation of the Baltic Sea climate change is questionable.

To illustrate the long-term adjustment of the stratification to the forcing, a $100 \mathrm{yr}$ time integration was run starting from the same initial conditions as before. The same $10 \mathrm{yr}$ forcing fields (the RCA model scenario run) were then used repeatedly 10 times. The water-level data from the Kattegat were, as before, taken from the period 1985 to 1995, which included the major inflow in 1992-1993. We therefore assumed that 1 major inflow event could occur once during each $10 \mathrm{yr}$ 
a) The E. Gotland Basin salinity, control run

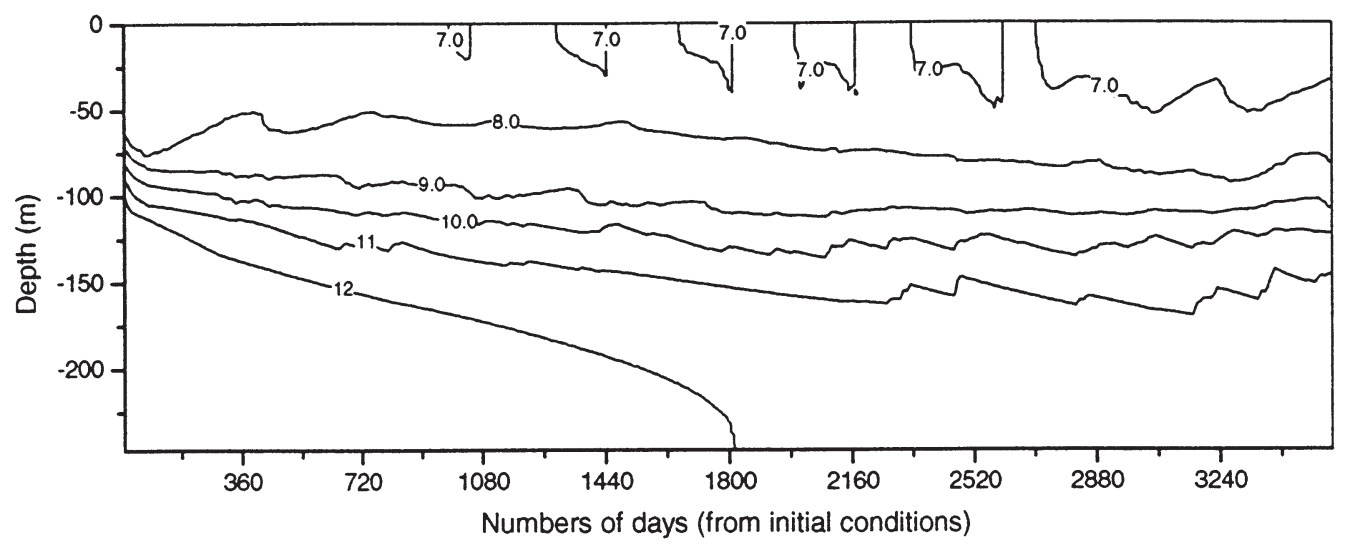

b) The E. Gotland Basin salinity, scenario run

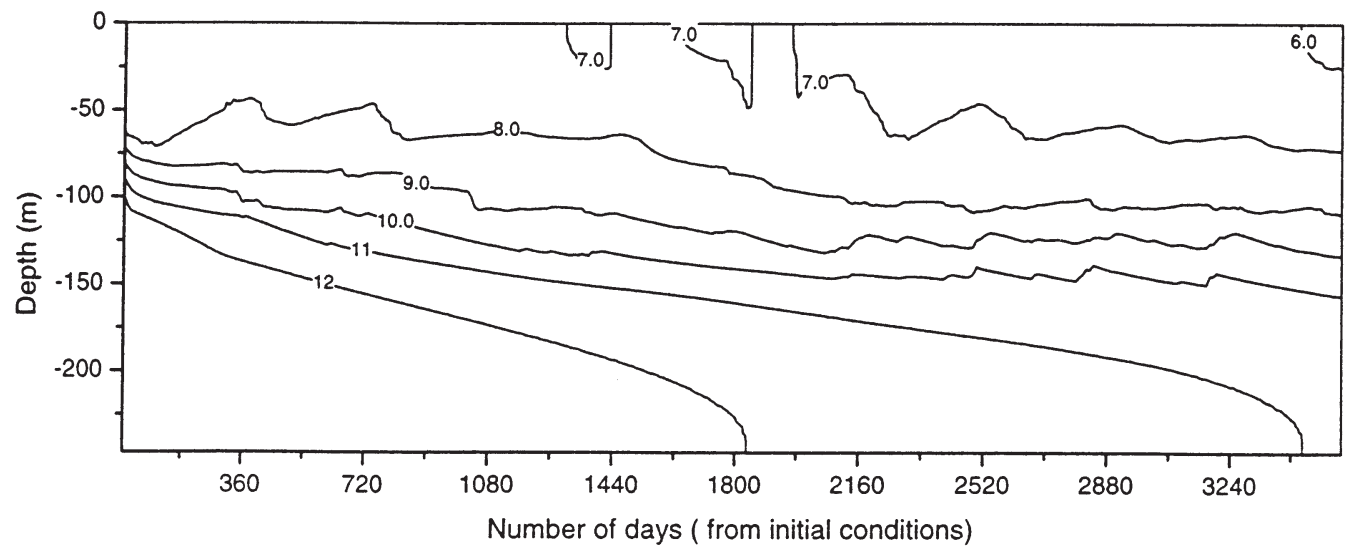

Fig. 9. Calculated vertical structure of salinity in the Eastern Gotland Basin based on (a) control and (b) scenario forcing fields

period. The salinity structures in the Eastern Gotland Basin after 50 and $100 \mathrm{yr}$ are illustrated in Fig. 10. The increased bottom salinity at the end of the $100 \mathrm{yr}$ run (Fig. 10b) reflects an inflow with a salinity of about 5 psu lower than in the standard run (Fig. 8b).

Even though the salinity structure in the 50 and $100 \mathrm{yr}$ simulations differed quite a lot from the $10 \mathrm{yr}$ simulation, the calculated sea-surface temperatures and extent of ice did not deviate significantly. The reason can be explained by studying Figs. $9 \& 10$, in which the vertical salinity structures are quite similar and by remembering that the thermodynamic time scale is short (Omstedt \& Rutgersson 2000). In the calculations the wind and in- and outflows were exactly the same in all $10 \mathrm{yr}$ spin-up simulations; the surface mixed layer therefore did not change in the different $10 \mathrm{yr}$ runs. This again illustrates the drawback of using short time slices for scenario runs. The vertical structures of the scenario run (Fig. 10b) and of the present Baltic Sea (Fig. 8b) show similarity; the salinity is reduced by about 5 psu from surface to bottom. This implies that the salinity of the entrance area has changed by approximately the same amount. In Gustafsson (1997) it was found that for increases of freshwater supply the salinity of the Baltic Sea and the surface layer in the Kattegat are indeed reduced by the same magnitude. This is, however, not the case for climate changes of wind and/or sea levels. A comparison between the 2 different Baltic Sea models is illustrated in Fig. 11. In the figure we illustrate the observed salinity structure in the Arkona Basin based upon present climate conditions (1980 to 1995) and corresponding calculation using the PROBE-Baltic model. The median salinity profile in the Arkona Basin based on the PROBE-Baltic model between the Years 90 and 100 in the scenario run and the corresponding calculation with the steadystate model by Gustafsson (1997) are also shown. Both ocean models indicate a large reduction in salinity compared to the present climate conditions. We can again notice that the difference between today's cli- 
a) The E. Gotland Basin salinity, scenario run

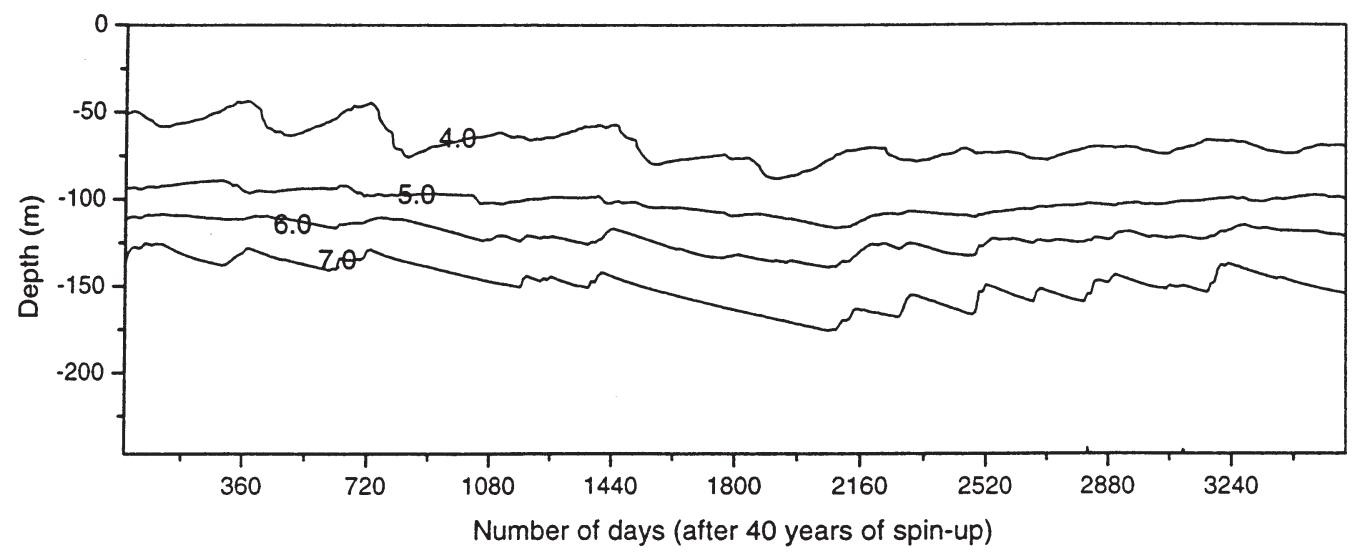

b) The E. Gotland Basin salinity, scenario run

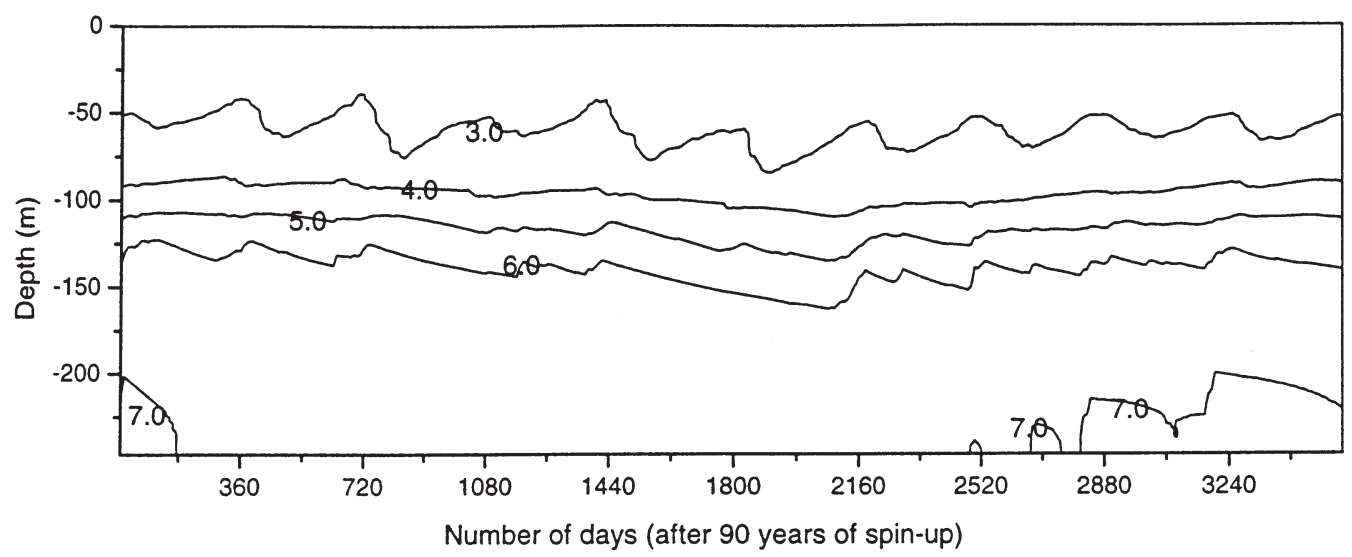

Fig. 10. Calculated vertical structure of salinity in the Eastern Gotland Basin based on scenario forcing fields after (a) 50 and (b) 100 yr of spin-up time

The Arkona Basin salinity (psu)

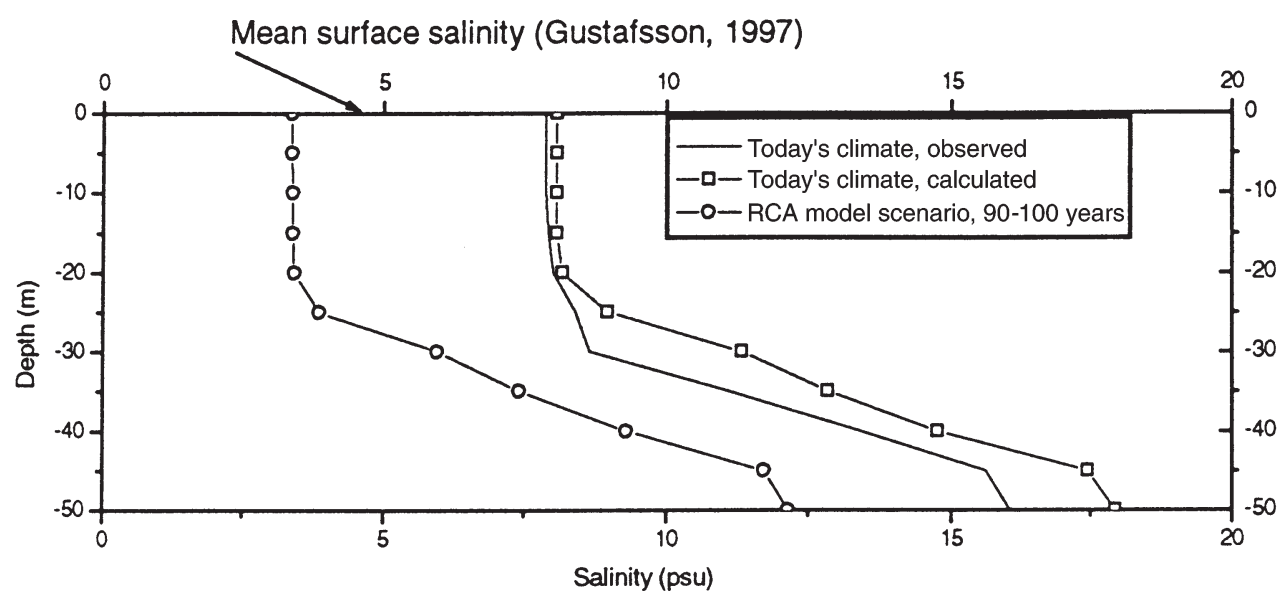

Fig. 11. Salinity in the Arkona Basin as modelled by the 2 ocean models. The PROBE-Baltic model calculations during standard run (-口-) are compared with observations (---) from the Arkona Basin (Stn BY2) using median profiles from the period 1980 to 1995. The results, with calculations according to the scenario run, from the PROBE-Baltic model and the model by Gustafsson (1997) are also illustrated (-O- and an arrow, respectively) 
mate and the scenario run gives a similar salinity change from surface to bottom. The explanation is that when the freshwater input to the Baltic Sea is increased, the salinity in the outflowing surface water is reduced and the salinity in the Kattegat is reduced. This reduces the salinity in the inflowing deep water to the Baltic Sea, and a decreasing salinity can been seen in the deeper layers.

\section{DISCUSSION}

This work illustrates how Baltic Sea modelling can be used to interpret climate atmosphere models. Based on forcing data from the climate models, the Baltic Sea salinity and annual maximum extent of ice can be used as integral properties to check the quality of the climate models. In the present work we have assumed the same initial conditions in both the control and the scenario runs. This could be justified for the sea-surface temperatures and for sea ice as the thermodynamic memory of the Baltic Sea is short, probably less than 1 yr (Omstedt \& Rutgersson 2000). For the vertical structure of the Baltic Sea and in particularly salinity this is, however, not appropriate. Due to the reduced exchange through the Baltic Sea entrance area, with a typical freshwater residence time of about $34 \mathrm{yr}$ (Winsor et al. 2000), simulations of time periods of $10 \mathrm{yr}$ are too short. This implies that for Baltic Sea climate studies the whole scenario run from the present to the year 2100 needs to be considered.

In the PROBE-Baltic model calculation we used the same forcing data from the N orth Sea, represented by sea levels in Kattegat from 1985 to 1995 with 1 major inflow included. This is of course an oversimplification and needs to be studied in much more detail.

For all calculations the ocean models were run as stand-alone models. The coupling between the atmosphere and ocean or between the atmosphere and ice were thus not dealt with. In the future we need to run coupled atmospheric, ocean and land-surface models to investigate the climate response. One could then expect both positive and negative feedback mechanisms. For example, a colder atmosphere will generate more ice, which will then cool the atmosphere even more. An interesting question is whether regional coupled models will reduce or enhance the strong climate warming signal that is simulated in most GCM runs.

Even though more efforts are needed to improve the climate modelling, the implications from the present calculations are that climate warming can be expected to reduce the extent of sea ice and the salinity in the Baltic Sea. This will of course have a strong influence on the biological systems in the Baltic Sea. For example, both the Baltic Sea cod and seaweed are very sen- sitive to salinity with respect to reproduction (Serrao et al. 1996, Vallin et al. 1999). M atthäus (1995) has also pointed out the importance of the Baltic Sea in climate research, as it has long time series of observations and is a system that is most sensitive to fluctuations in forcing. Backhaus (1996) concluded that the Baltic Sea probably is more sensitive to climate change than the North Sea because of a stronger coupling between temperature and salinity stratification.

\section{CONCLUSIONS}

In this work we have used oceanographic models of the Baltic Sea as a tool to interpret results from the first simulations with the Rossby Centre regional climate atmosphere (RCA) model. The purpose was to obtain a first scenario of the future state of the Baltic Sea and to review the consistency of the water cycle and heat balance produced by RCA model. The RCA model was used to improve the much coarser results from the coupled ocean-atmosphere GCM model HadCM 2 through dynamic downscaling. For the river-runoff simulations a large-scale hydrological model forced by the RCA model was also applied. Two types of ocean models were used to interpret the RCA model, one transient and one steady-state model.

The main conclusions may be summarised as follows:

(1) Baltic Sea modelling can serve as a useful tool when reviewing atmospheric climate models and indicates that the heat balance (as measured by seasurface temperature and extent of ice) can be quite realistically reproduced for the present climate conditions if dynamic downscaling is used. However, the water cycle (net precipitation over the open sea and river runoff) shows a freshwater input to the Baltic Sea that is too large and therefore needs to be improved.

(2) The use of short time slice periods of $10 \mathrm{yr}$ when studying future climate-change conditions are questionable, due to the long freshwater residence time and therefore long stratification spin-up time in the Baltic Sea.

(3) The scenario run indicates strong impacts on both the water cycle and the heat balance, with increased sea-surface temperatures, a much reduced extent of sea ice and reduced salinity. The reduced salinity implies possible serious effects on the future marine life in the Baltic Sea.

Acknowledgements. The authors thank Anders Ullerstig for providing the meteorological forcing field and Phil Graham for the river runoff calculations. We would also like to thank Markku Rummukainen and J ouni Räisänen for valuable discussion, J örgen Sahlberg and Peter Winsor for plotting sup- 
port, Lena Kautsky for interesting discussion related to fucus and salinity and Markus Meier for a comment on an earlier draft of the paper. This work is part of the Swedish Regional Climate M odelling Programme (SWECLIM) and was financed by the Swedish Strategic Environmental Research Foundation (MISTRA) and the Swedish Meteorological and Hydrological Institute (SM HI). The contribution by B.G. was done as a part of the BASYS project under EU-MAST contract MAS3CT96-0058.

\section{LITERATURE CITED}

Backhaus J O (1996) Climate-sensitivity of European marginal seas, derived from the interpretation of modelling studies. J Mar Syst 7:361-382

BALTEX (1995) Baltic Sea Experiment BALTEX. Initial implementation plan. International BALTEX Secretariat, Publ. No. 2, GKSS Research Center, Geesthacht

Bergström S, Forsman A (1973) Development of a conceptual deterministic rainfall-runoff model. N ordic Hydrol 4:147-170

Bergström S (1995) The HBV model. In: Singh VP (ed) Computer models of watershed hydrology. Water Resources Publications, Highlands Ranch, CO, p 443-476

Bergström S, Carlsson B (1994) River runoff to the Baltic Sea: 1950-1990. Ambio 23:280-287

Bergström S, Graham PL (1998) On the scale problem in hydrological modelling. J Hydrol 211:253-265

Graham PL (1999) Modeling runoff to the Baltic Sea. Ambio 27(4):328-334

Graham PL, Jacob D (2000) Using large-scale hydrologic modeling to review runoff generation processes in GCM climate models. M eteorol Z 9:43-51

Gustafsson, B (1997) Interaction between Baltic Sea and North Sea. D Hydrol Z 49, No 2/3, 165-183

Gustafsson B (2000a) Time-dependent modeling of the Baltic Entrance Area Part 1: Quantification of circulation and residence times in the Kattegat and the Straits of the Baltic Sill. Estuaries (in press)

Gustafsson B (2000b) Time-dependent modeling of the Baltic Entrance Area. Part 2: Water and salt exchange of the Baltic Sea. Estuaries (in press)

Haapala J , Leppäranta M (1996) Simulating the Baltic Sea ice season with a coupled ice-ocean model. Tellus 48A: 622-643

Haapala J , Leppäranta M (1997) The Baltic Sea ice season in changing climate. Boreal Environ Res 2:93-108

HELCOM (1986) Water balance of the Baltic Sea. Baltic Sea Environment Proceedings, 16, Helsinki

Huber K, Kleine E, Lass HU, Matthäus W (1994) The major Baltic inflow in J anuary 1993-M easurements and modelling results. D Hydrol Z 46(2):103-114

IPCC (Intergovernmental Panel on Climate change) (1996) Climate change 1995 . The science of climate change. Houghton JT, Meira Filho LG, Callander BA, Harris N, Kattenberg A, Maskall K (eds) Cambridge University Press, Cambridge

J acob D, Windelband M, Podzun R, Graham PL (1997) Investigation of water and energy cycles of the Baltic Sea using global and regional climate models. In: XXII EGS Assembly, Vienna, April 21-25, 1997. International BALTEX Secretariat, Publ 8. GKSS Research Center, Geesthacht, p 107-115 (extended abstract)

J akobsen F (1997) Hydrographic investigation of the Northern Kattegat front. Cont Shelf Res 17(5):533-554

Jacobsen JP (1925) Die Wasserumsetzung durch den Öresund, den Grossen und den Kleinen Belt. Medd Komm
Havunders Ser Hydr 2:9

J acobsen TS (1980) The Belt Project: sea-water exchange of the Baltic - measurements and methods. National Agency of Environmental Protection, Denmark

J ohannesson T, J onsson T, Källen E, Kass E (1995) Climate change scenarios for the Nordic Countries. Clim Res 5: 181-195

J ohns TC, Carnell RE, Crossley J F, Gregory J M, M itchell J FB, Senior CA, Tett SFB, Wood RA (1997) The second Hadley Centre coupled ocean-atmosphere GCM : model description, spinup and validation. Clim Dyn 13:103-134

Knudsen M (1899) De hydrografiske forhold i de danske farvande indenfor Skagen i 1894-98. (The hydrographic conditions in the Danish waters inside Skagen in 1894-98) Komm For Vidensk Unders I de danske farvande 2:2

Knudsen M (1900) Ein hydrographischer Lehrsats. Ann Hydr 28:316-320

Källén E (1996) HIRLAM documentation manual. System 25. SMHI, N orrköping

Lehmann A (1995) A three-dimensional baroclinic eddyresolving model of the Baltic Sea. Tellus 47A:1013-1031

Lehmann A, Hinrichsen $\mathrm{HH}$ (2000) On the wind-driven and thermocline circulation of the Baltic Sea. Phys Chem Earth B 25(2):183-189

Lindström G, J ohansson B, Persson M , Gardelin M , Bergström S (1997) Development and test of the distributed HBV-96 model. J Hydrol 201:272-288

Matthäus, W (1995) Natural variability and human impacts reflected in long-term changes in the Baltic Deep water conditions-a brief review Dtsch Hydrogr Z 47:47-65

Meier HEM (1996) Ein regionales M odell der westlichen Ostsee mit offenen Randbedingungen und Datenassimilation. Ber IfM Kiel Nr 284

Meier HEM (1999) First results of multi-year simulations using a 3D Baltic Sea model. SMHI Rep Oceanogr, RO 27. SMHI, Norrköping

Omstedt A (1987) Water cooling in the entrance of the Baltic Sea. Tellus 39A:254-265

Omstedt A (1990) Modelling the Baltic Sea as thirteen subbasins with vertical resolution. Tellus 42A:286-301

Omstedt A, Axell LB (1998) Modelling the seasonal, interannual, and long-term variations of salinity and temperature in the Baltic proper. Tellus 50A:637-652

Omstedt A, Nyberg L (1996) Response of Baltic Sea ice to seasonal, interannual forcing and climate change. Tellus 48A: 644-662

Omstedt A, Rutgersson A (2000) Closing the water and heat cycles of the Baltic Sea. M eteorol Z 9:53-60

Omstedt A, M euller L, Nyberg L (1997) Interannual, seasonal and regional variations of precipitation and evaporation over the Baltic Sea. Ambio 26:484-492

Räisänen J A (1994) Comparison of the results of seven GCM experiments in the N orthern Europe. Geophysica 30(1-2): 3-30

Räisänen J A (2000) $\mathrm{CO}_{2}$-induced climate change in northern Europe: comparison of 12 CMIP2 experiments SM HI Rep M eteorol Climatol, RM K 87. SM HI, N orrköping

Räisänen J, Döscher R (1998) Simulation of present-day climate in Northern Europe in the HadCM 2 OAGCM. SM HI Rep M eteorol Climatol, RMK 84. SM HI, Norrköping

Räisänen J , Rummukainen M, Ullerstig A, Bringfelt B, Hansson U, Wille'n U (1999) The first Rossby Centre Regional Climate Scenario-dynamical downscaling of $\mathrm{CO}_{2}$ induces climate change in the HadCM 2 GCM. SMHI Rep M eteorol Climatol, RM K 85. SM HI, N orrköping

Rummukainen M, Räisänen J, Ullerstig A, Bringfelt B, Hansson U, Graham PL, Wille'n U (1998) RCA-Rossby Centre 
regional atmospheric climate model: model description and results from the first multi-year simulation. SM HI Rep, RMK 83. SM HI, Norrköping

Sayin E, Krauss W (1996) A numerical study of the water exchange through the Danish Straits. Tellus 48A:324-341

Schrum C, Backhaus J O (1999) Sensitivity of atmosphereocean exchange and heat content in North Sea and Baltic Sea - a comparative assessment. Tellus 51A(4):526-549

Schuurmans C, Cattle H, Choisnel E, Dahlström B, Gagaoudaki C, Müller-Westermeier G, Orfila B (1995) Climate of Europe Recent variation, present state and future prospects. Royal Netherlands M eteorological Institute, De Bilt

Seinä A (1993) Ice time series of the Baltic Sea. Proc. 1st Workshop on the Baltic Sea Ice Climate, Tvärminne, August 24-28, 1993. Department of Geophysics, University of Helsinki, Rep Ser Geophy 27:87-90

Seinä A, Palosuo E (1993) The classification of the maximum annual extent of ice cover in the Baltic Sea 1720-1992. Meri 20:5-20 (in Finnish)

Serrao EA, Kautsky L, Brawley SH (1996) Distributional success of the marine seaweed Fucus vesiculosus $L$. in the brackish Baltic Sea correlates with osmotic capabilities of Baltic gametes. Oecologia 107:1-12

Soskin IM (1963) Long term changes in the hydrological characteristics of the Baltic Sea. Hydrometeor Press, Leningrad (in Russian)

Editorial responsibility: Hans von Storch,

Geesthacht, Germany
Stendel M, Roeckner E (1998) Impacts of horizontal resolution on simulated climate statistics in ECHAM4. Report No 253, M ax-Planck-Institut für M eteorologie, Hamburg

Stigebrandt A (1983) A model for the exchange of water and salt between the Baltic and the Skagerrak. J Phys Oceanogr 13(3):411-427

Tinz B (1996) On the relation between annual maximum extent of ice cover in the Baltic Sea and sea level pressure as well as air temperature field. Geophysica 32(3): 319-341

Tinz B (1998) Sea ice winter severity in the German Baltic in a greenhouse gas experiment. German J Hydrol 50(1): 31-43

Vallin L, Nissling A, Westin L (1999) Potential factors influencing reproductive success of Baltic cod, Gadus morhua: a review. Ambio 28(1):92-99

Winkel-Steinberg N, Backhaus J O, Pohlmann T (1991) On the estuarine circulation within the Kattegat. In: Prandle D (ed) Dynamics and exchanges in estuaries and the coastal zone. Springer-Verlag, New York, p 231-251

Winsor P, Rodhe J, Omstedt A (2000) Baltic Sea ocean climate- an analysis of 100 years of hydrographic data with the focus on the fresh water budget. Clim Res (in press)

Witting R (1918) Havsytan, Geoidytan och landhöjningen utmed Baltiska Hafvet. Fennia 39:5

Wyrtki K (1954) Schwankungen im Wasserhaushalt der Ostsee. Dtsch Hydrol Z 7:91-129

Submitted: J uly 23, 1999; Accepted: February 6, 2000

Proofs received from author(s): M ay 5, 2000 